\title{
DESAIN MANUFAKTUR BRACKET ALUMINIUM
}

\author{
Rudianto Raharjo, Teguh Dwi Widodo, Redi Bintarto \\ Jurusan Teknik Mesin Fakultas Teknik Universitas Brawijaya \\ JI. MT. Haryono 167 Malang 65145 \\ Telp/ Fax (0341) 8051752 \\ E-mail: rudiantoraharjo@ub.ac.id
}

\begin{abstract}
Machining is one of the processes in a manufacturing of a product. Manufacturing design is needed for improving the quality of a product. The desired manufacturing process is the achievement of a product with a smooth level of roughness and a short time. Bracket is one component of a series of machines. Work on bracket using CNC milling and Turning machine. The material used is aluminum alloy 6063. The main variables in this machining process are the speed of feeding, cutting speed and feeding motion. The results achieved in the machining process of this bracket are for the roughness on the surface of the N5 with Ra (ideal) $=0.4 \mu \mathrm{m}$ of $R a$ (actual) $=0.410 \mu \mathrm{m}$. As for the roughness of $\mathrm{N} 6$ with $\mathrm{Ra}$ (ideal) $=0,8 \mu \mathrm{m}$ obtained result $\mathrm{Ra}$ (actual) $=0,832 \mu \mathrm{m}$ and 0,625 $\mu \mathrm{m}$. Total machining time for one workpiece are 1 hour 57 minutes 25 seconds.
\end{abstract}

Keywords: surface roughness, cutting speed, feed rate, depth of cut.

\section{PENDAHULUAN}

Permintaan pasar akan produk manufaktur berbahan dasar logam yang berkualitas dan variatif kiat meningkat seiring dengan ditemukan berbagai macam metode dalam memproduksi barang. Produk yang berkualitas ditentukan dari fungsi dan jangka waktu penggunaan. Jangka waktu pemakaian produk juga ditentukan oleh pemilihan material, proses pengerjaan dan Permesinan, dan kontrol kualitas sebelum produk sampai ke tangan customer.

Proses Permesinan merupakan proses untuk mendapatkan geometri dan kualitas produk yang dikehendaki dengan cara memotong logam (ditunjukkan dengan terbentuknya geram/chips) [1]. Dalam perkembangannya, sesuai dengan kemajuan teknologi pembuatan komponen logam yang lain (proses penuangan/casting dan proses pembentukan/forming), proses Permesinan sampai saat ini masih tetap merupakan proses yang paling banyak digunakan $60 \%$ sampai dengan $80 \%$ ) didalam membuat suatu mesin yang komplit [2].

Oleh karena itu, proses Permesinan merupakan salah satu parameter penting dalam industri manufaktur. Keberadaannya menjadi salah satu faktor penentu dalam mempengaruhi kinerja suatu produk, terutama yang berbahan dasar logam [3].
Proses Permesinan dapat dilakukan hampir pada semua bahan teknik, sekalipun hanya menggerinda atau menghaluskan [4]. Salah satu aplikasinya yakni dalam pembuatan bracket. Untuk pembuatan bracket dapat menggunakan mesin CNC dengan/tanpa proses pengecoran terlebih dahulu. Nantinya bracket dapat melengkapi proses perakitan khususnya pada sealed shaft unit (rangkaian poros tertutup). Sealed shaft unit merupakan rangkaian dari beberapa komponen dalam sebuah konstruksi alat/mesin yang berfungsi sebagai penghalang / pengeblok keluar/masuknya cairan/gas, baik itu fluida proses maupun pelumas.

Berdasarkan geometri dari produk/komponen mesin yang variatif dan kompleks, maka proses Permesinan yang diterapkan beranekaragam dan dapat direncanakan langkah pengerjaan dengan urutan yang paling baik. Termasuk di dalamnya penentuan jenis pahat yang digunakan sesuai dengan urutan/langkah pengerjaan $[5,6]$. Penentuan kondisi pemotongan (cutting speed, feeding speed, depth of cut) juga perlu ditentukan sedemikian rupa guna mendapatkan komponen yang diminta [7]. Penentuan parameter dan proses Permesinan ini mengacu pada penggunaan waktu yang efisien dalam menghasilkan produk dan kualitas permukaan hasil Permesinan sesuai dengan desain yang dibuat [8]. Oleh karena itu, perlu adanya suatu 
rancangan konseptual guna memenuhi fungsi yang dimaksud, dimana agar tercapai minimal waktu Permesinan dan tingkat

\section{METODOLOGI PENELITIAN}

Metode yang akan digunakan di dalam perencanaan ini adalah true experimental design (percobaan desain secara nyata). Variabel bebas pada perencanaan ini adalah kedalaman pemotongan (depth of cut), gerak makan. Sedangkan variabel terikat adalah kekasaran permukaan. Dan variabel terkontrol pada pengerjaan adalah kecepatan potong sebesar $25 \mathrm{~m} / \mathrm{min}$.

\section{Desain Bracket}

Dimensi beserta tingkat kekasaran permukaan dari benda kerja yang ingin dicapai terlihat seperti lampiran [9]. Untuk gambar potongan sebagai berikut:
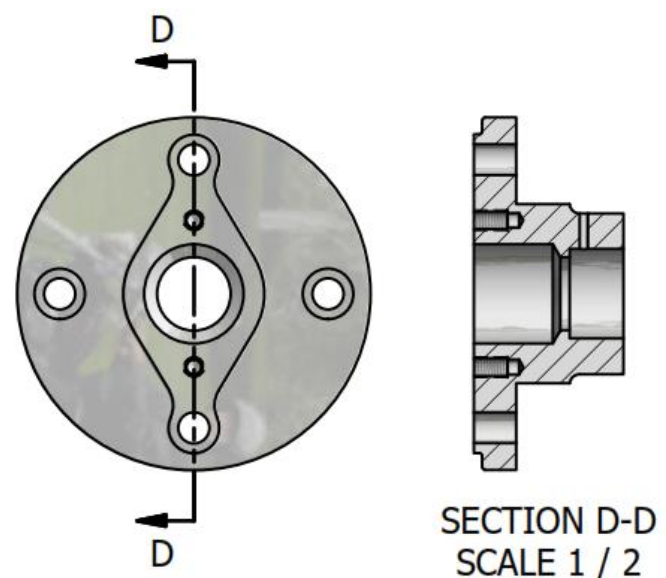

Gambar 1. Potongan benda kerja

\section{Pahat yang digunakan}

Bahan : pahat High Speed Steel

Tipe : Flat End Mill $(\varnothing 10 \mathrm{~mm}, \varnothing 16 \mathrm{~mm})$, Ball End Mill $(\varnothing 6 \mathrm{~mm}, \varnothing 7 \mathrm{~mm})$, Center Drill (Ø5 $\mathrm{mm})$, Drill (Ø5 mm, Ø19 mm, Ø25 mm)

Jumlah pisau : 4 (Flat End Mill), 2 (Center Drill, Drill, Ball End Mill)

Tingkat kekasaran disesuaikan dengan Tabel 1 [10]:

\begin{tabular}{|c|c|c|c|c|}
\hline $\begin{array}{c}\text { Kelas } \\
\text { kekasaran }\end{array}$ & $\begin{array}{c}\text { Harga C.L.A } \\
(\mu \mathrm{m})\end{array}$ & $\begin{array}{c}\text { Harga Ra } \\
(\mu \mathrm{m})\end{array}$ & Toleransi ${ }^{\mathrm{N}} \cdot 25 \%$ & \begin{tabular}{|c|} 
Panjang \\
sampel $(\mathrm{mm})$ \\
\end{tabular} \\
\hline N1 & 1 & 0.0025 & $0.02-0.04$ & 0.08 \\
\hline N2 & 2 & 0.05 & $0.04-0.08$ & \\
\hline N3 & 4 & 0.0 & $0.08-0.15$ & 0.25 \\
\hline N4 & 8 & 0.2 & $0.15-0.3$ & \\
\hline N5 & 16 & 0.4 & $0.3-0.6$ & \\
\hline N6 & 32 & 0.8 & $0.6-1.2$ & \\
\hline N7 & 63 & 1.6 & $1.2-2.4$ & \\
\hline N8 & 125 & 3.2 & $2.4-4.8$ & 08 \\
\hline N9 & 250 & 6.3 & $4.8-9.6$ & \\
\hline N10 & 500 & 12.5 & $9.6-18.75$ & \\
\hline N11 & 1000 & 25.0 & $18.75-37.5$ & 2.5 \\
\hline $\mathrm{N} 12$ & 2000 & 50.0 & $37.5-75.0$ & 8 \\
\hline
\end{tabular}

\section{Bahan yang digunakan}

Bahan yang digunakan untuk percobaan Permesinan ini adalah aluminium 6063 dengan karakteristik material sebagai berikut:

Tabel 2. Data Material Al-6063

$\begin{array}{ll}\mathrm{Si}(\%) & 0.588 \\ \mathrm{Fe} \mathrm{( \% )} & 0.3127 \\ \mathrm{Cu} \mathrm{( \% )} & 0,1620 \\ \mathrm{Mn}(\%) & 0.0289 \\ \mathrm{Mg}(\%) & 0.747 \\ \mathrm{Cr}(\%) & 0.0765 \\ \mathrm{Zn} \mathrm{( \% )} & 0.0396 \\ \mathrm{Ni} \mathrm{( \% )} & 0.0055 \\ \mathrm{~Pb} \mathrm{( \% )} & 0.0031 \\ \mathrm{Al}(\%) & 61\end{array}$

Cairan pendingin yang digunakan adalah water soluble oil yang tergolong dalam cairan emulsi. Merupakan campuran antara pengemulsi dan air. Penyemprotan dengan cara dikucurkan melalui tiga saluran yang langsung mengenai bidang aktif pemotong

\section{Pelaksanaan Permesinan}

Program Permesinan yang digunakan dalam pelaksanaan didapatkan dari hasil program aplikasi simulasi MASTER CAM X5. Secara garis besar adalah pengasaran permukaan lingkaran besar, kemudian dilakukan pembentukan profil sesuai desain. Selanjutnya melubangi bagian tengah dan kemudian mengerjakan lingkaran berdiameter kecil dengan bentuk sesuai desain, untuk selanjutnya melubangi di sisi yang lain. Dan pelebaran lubang ditengah menggunakan mesin bubut hingga di dapat dimensi sesuai gambar. Pada perencanaan ini mesin CNC yang digunakan adalah CNC Milling Machine EMCOVMC200 dengan Spindle Range antara 
150 - $4500 \mathrm{rpm}$ dan feed motor $1.2 \mathrm{Kw}$. Percobaan Permesinan milling dilakukan di Bengkel CNC Departemen Mesin dan CNC PPPPTK - VEDC Malang serta uji kekasaran di Laboratorium Metrologi Industri Jurusan Mesin Fakultas Teknik Universitas Brawijaya dengan alat Surface Roughness Tester SJ 301.

\section{HASIL DAN PEMBAHASAN}

Dimensi awal benda kerja setelah dilakukan pengecoran dan pemotongan saluran penuangan [11-13]:

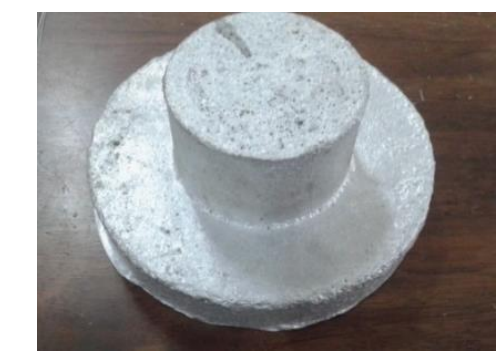

Gambar 2. Benda kerja hasil cor

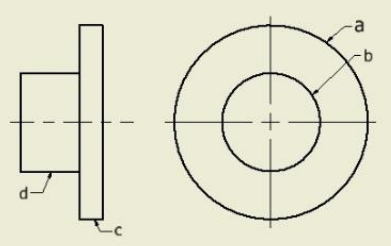

Gambar 3. Dimensi awal

Setelah dilakukan permesinan didapatkan geometri sebagai berikut:

Tabel 3. Dimensi Benda Kerja

\begin{tabular}{llll}
\hline Bagian & $\begin{array}{l}\text { Dimensi } \\
(\mathrm{mm})\end{array}$ & Bagian & $\begin{array}{l}\text { Dimensi } \\
(\mathrm{mm})\end{array}$ \\
\hline $\mathrm{a}$ & 126.35 & $\mathrm{c}$ & 16.25 \\
$\mathrm{~b}$ & 64.59 & $\mathrm{~d}$ & 39.23 \\
\hline
\end{tabular}

Geometri pahat freis dan gurdi adalah sebagai berikut:

Tabel 4. Geometri Pahat

\begin{tabular}{lll}
\hline \multirow{3}{*}{ Milling } & Sudut helix $(\phi)$ & $=38^{\circ}$ \\
& Sudut utama $(\mathrm{Kr})$ & $=90^{\circ}$ \\
& Sudut bantu $\left(\mathrm{Kr}^{\prime}\right)$ & $=5^{\circ}$ \\
\multirow{3}{*}{ Gurdi } & Sudut puntir $\left(\mathrm{Y}_{\mathrm{f}}\right)$ & $=23^{\circ}$ \\
& Sudut ujung $(2 \mathrm{Kr})$ & $=118^{\circ}$ \\
& Sudut bebas $\mathrm{s}\left(\mathrm{a}_{\mathrm{f}}\right)$ & $=20^{\circ}$ \\
\hline
\end{tabular}

Penentuan kondisi pemotongan adalah sebagai berikut:
Tabel 5. Kondisi Pemotongan

\begin{tabular}{|c|c|c|c|}
\hline & $\begin{array}{l}\mathrm{a} \\
(\mathrm{mm})\end{array}$ & $\mathrm{f}_{\mathrm{z}} \mathrm{mm} / \mathrm{gigi}$ & $\mathrm{v}(\mathrm{m} / \mathrm{min})$ \\
\hline & Pengasara & & \\
\hline milling & 0.75 & 0.2 & 25 \\
\hline & Penghalus & an & \\
\hline & $\begin{array}{l}\mathrm{N} 5=0.25 \\
\mathrm{~N} 6=0.5\end{array}$ & $\begin{array}{l}\text { N5 }=0.007 \\
\text { N6 }=0.004\end{array}$ & 25 \\
\hline drilling & 2.5 & 0.06 & 17.97 \\
\hline $\begin{array}{l}\text { erikut } \\
\text { MCOVI } \\
\text { emasan }\end{array}$ & $\begin{array}{l}\text { mesin } \\
\text { c200 }\end{array}$ & $\begin{array}{ll}\text { NC } & \text { Mil } \\
\text { erg } & \text { dig } \\
\text { rig: } & \end{array}$ & $\begin{array}{l}\text { Machine } \\
\text { kan dan }\end{array}$ \\
\hline
\end{tabular}

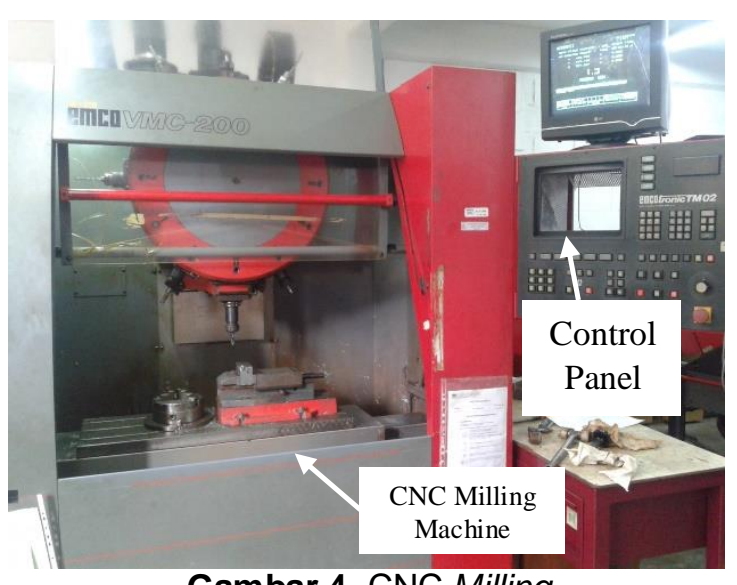

Gambar 4. CNC Milling

Secara garis besar, perencanaan proses Permesinan bracket ini terdapat beberapa poin, diantaranya:

1. Dalam proses Permesinan bracket ini digunakan kecepatan pemotongan yang konstan. karena dengan kondisi ini akan dihasilkan nilai waktu pemotongan dan Permesinan yang lebih singkat jika dibandingkan dengan nilai putaran poros utama atau putaran spindle yang dijaga konstan. Dengan kecepatan konstan, untuk setiap penurunan diameter pahat potong, maka putaran poros akan lebih besar.

2. Nilai kondisi pemotongan proses milling didasarkan pada:

- Proses Pengasaran

Pemilihan kedalaman pemotongan maksimum guna mempercepat penghasil geram. Gerak makan dipilih berdasarkan bahan dan pahat yang digunakan. Sedangkan pemilihan nilai 
kecepatan potong baik pada proses pengasaran maupun penghalusan mengacu pada karakteristik pemotongan pada pahat yang dipakai.

- Proses penghalusan

Kondisi pemotongan untuk proses penghalusan, gerak makan disesuaikan dengan nilai kekasaran permukaan yang ingin didapatkan Sedangkan kedalaman potong direncanakan sedemikian dengan penurunan interval sebesar $0.25 \mathrm{~mm}$ dari nilai kedalaman potong maksimum.

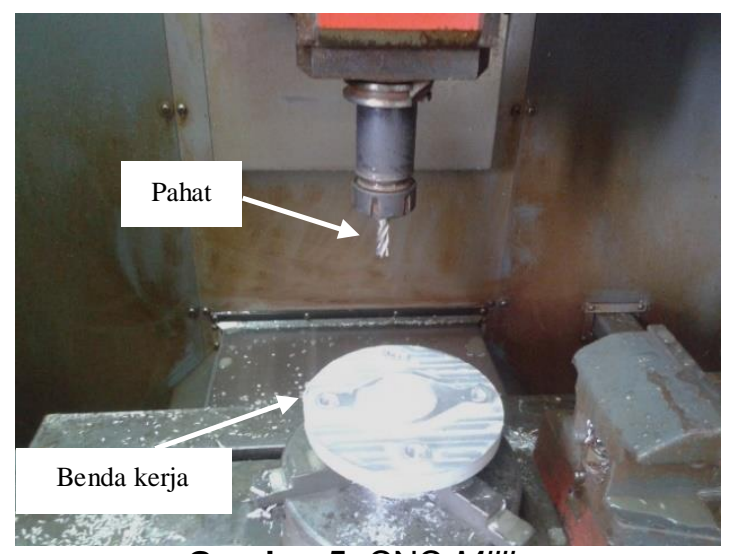

Gambar 5. CNC Milling

Secara garis besar, perencanaan proses Permesinan bracket ini terdapat beberapa poin, diantaranya:

3. Dalam proses Permesinan bracket ini digunakan kecepatan pemotongan yang konstan. karena dengan kondisi ini akan dihasilkan nilai waktu pemotongan dan Permesinan yang lebih singkat jika dibandingkan dengan nilai putaran poros utama atau putaran spindle yang dijaga konstan. Dengan kecepatan konstan, untuk setiap penurunan diameter pahat potong, maka putaran poros akan lebih besar.

4. Nilai kondisi pemotongan proses milling didasarkan pada:

- Proses pengasaran

Pemilihan kedalaman pemotongan maksimum guna mempercepat penghasil geram [14]. Gerak makan dipilih berdasarkan bahan dan pahat yang digunakan. Sedangkan pemilihan nilai kecepatan potong baik pada proses pengasaran maupun penghalusan mengacu pada karakteristik pemotongan pada pahat yang dipakai [15].

- Proses penghalusan

Kondisi pemotongan untuk proses penghalusan, gerak makan disesuaikan dengan nilai kekasaran permukaan yang ingin didapatkan Sedangkan kedalaman potong direncanakan sedemikian dengan penurunan interval sebesar $0.25 \mathrm{~mm}$ dari nilai kedalaman potong maksimum.

Hasil proses Permesinan benda kerja adalah sebagai berikut:
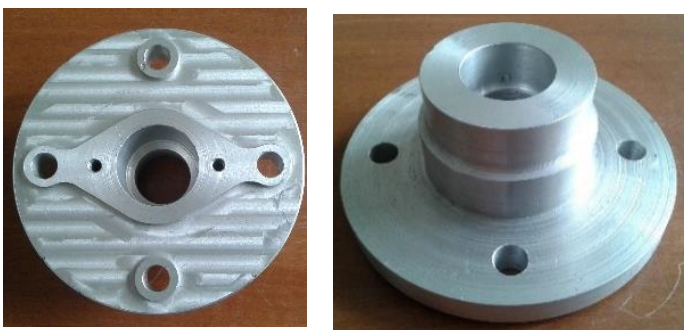

Gambar 6. Hasil Permesinan

Nilai kekasaran aktual yang dihasilkan dari proses Permesinan yang direncanakan adalah sebagai berikut:

Tabel 6. Nilai kekasaran permukaan

\begin{tabular}{lllll}
\hline No & $\begin{array}{l}\text { Tingkat } \\
\text { kekasar } \\
\text { an, ISO } \\
\text { Number }\end{array}$ & $\begin{array}{l}\text { Ra } \\
\text { ideal } \\
(\mu \mathrm{m})\end{array}$ & $\begin{array}{l}\text { Ra aktual } \\
\text { (sebelum } \\
\text { finishing) } \\
(\mu \mathrm{m})\end{array}$ & $\begin{array}{l}\text { Ra aktual } \\
\text { (sesudah } \\
\text { finishing) } \\
(\mu \mathrm{m})\end{array}$ \\
\hline 1. & N5 & 0.4 & - & \\
2. & N6 & 0.8 & 2.354 & 0.410 \\
3. & N6 & 0.8 & 3.122 & 0.832 \\
\hline
\end{tabular}

Secara keseluruhan urutan proses pengerjaan benda dari dimensi awal yang didapatkan dari penggerindaan coran hingga benda jadi disajikan dalam Tabel 7. 
Tabel 7. Urutan Proses Permesinan

\begin{tabular}{|c|c|c|c|c|c|c|c|}
\hline No. & Kegiatan & do $(\mathrm{mm})$ & $\begin{array}{l}\mathrm{dm} \\
(\mathrm{mm})\end{array}$ & $\begin{array}{l}\mathrm{a} \\
(\mathrm{mm})\end{array}$ & $\begin{array}{l}\mathrm{fz} \\
\left(\mathrm{mm} \cdot \mathrm{rev}^{-1}\right)\end{array}$ & $\begin{array}{l}v \\
\left(\mathrm{~m} \cdot \mathrm{min}^{-}\right. \\
\left.{ }_{1}\right)\end{array}$ & $\begin{array}{l}\text { Pahat } \\
\text { Potong }\end{array}$ \\
\hline \multicolumn{8}{|c|}{ Pasang dan atur benda kerja pada cekam } \\
\hline \multicolumn{8}{|c|}{ Pasang dan atur pahat pada tool post } \\
\hline 1 & $\begin{array}{l}\text { Facing sisi terluar } \\
\text { lingkaran } \varnothing 125 \mathrm{~mm} \\
\text { dengan panjang } 15 \\
\mathrm{~mm}\end{array}$ & 126.35 & 125 & 0.5 & 0.007 & 25 & T219 \\
\hline 2 & $\begin{array}{l}\text { Roughing } \\
\text { permukaan atas } \\
\text { lingkaran } \varnothing 125 \mathrm{~mm}\end{array}$ & 16.25 & - & 0.75 & 0.2 & 25 & T219 \\
\hline 3 & $\begin{array}{l}\text { Finishing } \\
\text { permukaan atas } \\
\text { lingkaran } \varnothing 125 \mathrm{~mm}\end{array}$ & 16.25 & 15 & 0.5 & 0.007 & 25 & T219 \\
\hline 4 & $\begin{array}{l}\text { Buat } 4 \text { Lubang } \varnothing 11 \\
\text { mm dengan } \\
\text { kedalaman } 16 \mathrm{~mm}\end{array}$ & - & 11 & 0.5 & 0.007 & 25 & T219 \\
\hline 5 & Center drill Ø5mm & - & 5 & 0.75 & 0.2 & 25 & T1 \\
\hline 6 & $\begin{array}{l}\text { Drill } \varnothing 5 \mathrm{~mm} \text { dengan } \\
\text { panjang } \\
\text { pemotongan } 16 \mathrm{~mm}\end{array}$ & 5 & 10 & 2.5 & 0.06 & 17.97 & T60 \\
\hline 7 & Center drill Ø5mm & - & 5 & 2.5 & 0.4 & 25 & $\mathrm{~T} 1$ \\
\hline 8 & $\begin{array}{l}\text { Drill } \quad \varnothing 19 \mathrm{~mm} \\
\text { dengan panjang } 53 \\
\mathrm{~mm}\end{array}$ & 5 & 19 & 8.5 & 0.4 & 25 & T200 \\
\hline \multirow[t]{2}{*}{9} & $\begin{array}{l}\text { Drill } \quad \varnothing 25 \mathrm{~mm} \\
\text { dengan panjang } 53 \\
\mathrm{~mm}\end{array}$ & 19 & 25 & 12.5 & 0.4 & 25 & T260 \\
\hline & \multicolumn{7}{|c|}{ Lepas dan atur ulang benda kerja dengan posisi permukaan $\varnothing 125 \mathrm{~mm}$ berada di bawar } \\
\hline 10 & $\begin{array}{l}\text { Finishing sisi terluar } \\
\text { lingkaran } \\
\varnothing 63.45 \mathrm{~mm} \text { dengan } \\
\text { panjang } 38 \mathrm{~mm}\end{array}$ & 64.59 & 63.45 & 0.5 & 0.007 & 25 & T225 \\
\hline 11 & $\begin{array}{l}\text { Finishing sisi terluar } \\
\text { lingkaran } \\
\varnothing 63.45 \mathrm{~mm} \text { dengan } \\
\text { panjanng } 16 \mathrm{~mm}\end{array}$ & 63.45 & 57 & 0.5 & 0.007 & 25 & T225 \\
\hline 12 & Buat fillet $\varnothing 7 \mathrm{~mm}$ & - & 7 & 0.5 & 0.007 & 25 & T241 \\
\hline \multicolumn{8}{|c|}{ Lepas benda kerja dan atur pada cekam } \\
\hline \multicolumn{8}{|c|}{$\begin{array}{l}\text { Proses nomor } 14-18 \text { menggunakan mesin bubut, hal ini dikarenakan pahat yang dibutuhkan } \\
\text { tidak tersedia dalam perlengkapan mesin CNC }\end{array}$} \\
\hline 13 & $\begin{array}{l}\begin{array}{l}\text { Finishing } \\
\text { dengan } \\
28 \mathrm{~mm}\end{array} \\
\end{array}$ & 25 & 34.5 & 0.5 & - & 25 & HSS \\
\hline
\end{tabular}




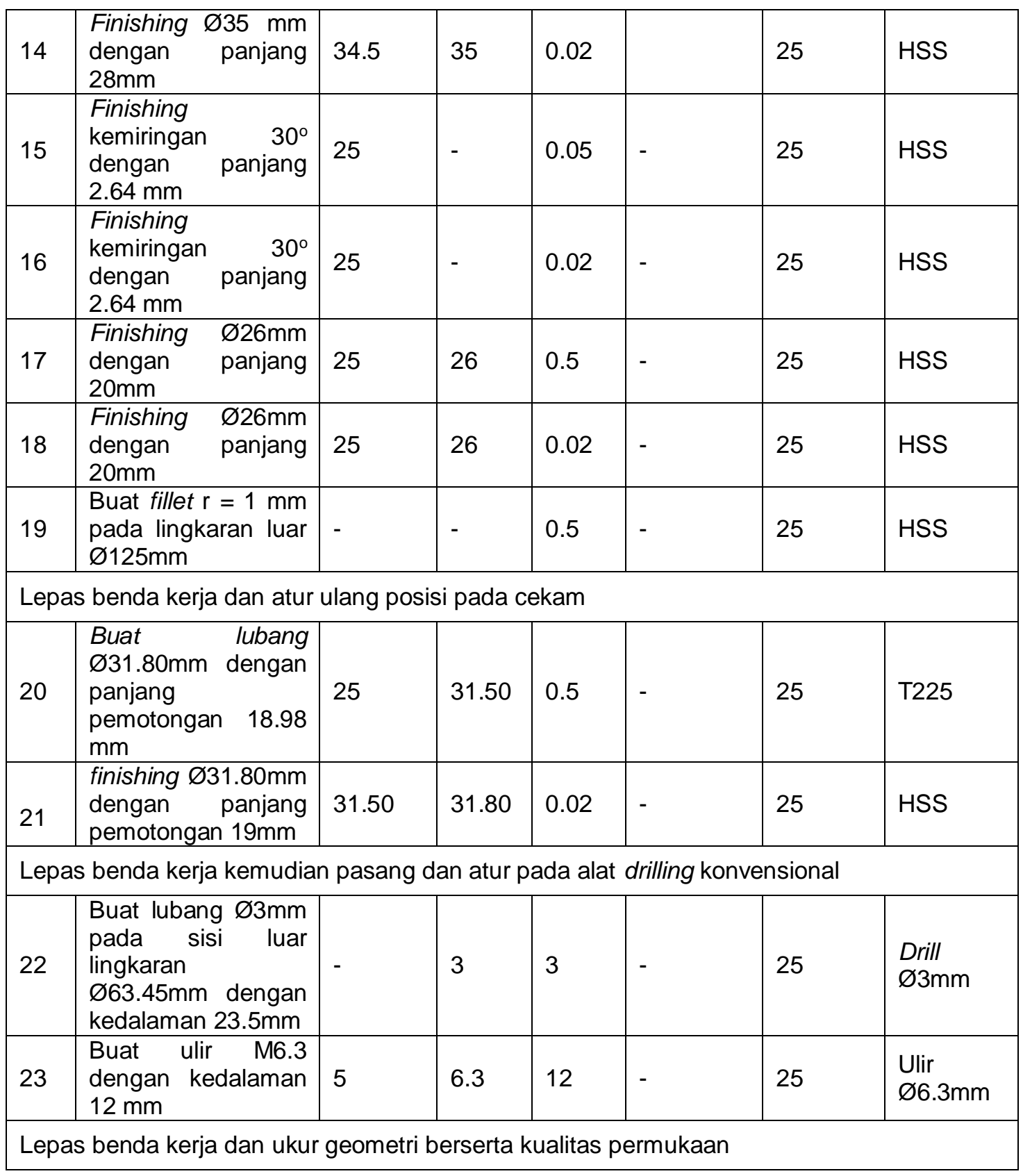

Berdasarkan Tabel 6, nilai kekasaran aktual untuk tingkatan N5 lebih tinggi dibandingkan nilai idealnya, hal ini dikarenakan.

- Pada saat proses penghalusan dengan bubut, putaran spindle yang tinggi mengakibatkan geram ikut beputar di dalam dinding benda kerja, sehingga mempengaruhi kualitas permukaan.

- Dengan kedalaman potong yang besar nilai atau gerak makan yang tinggi, disebabkan mengakibatkan pojok pahat menerima beban kejut saat proses permulaan pemotongan.

Menempelnya serpihan potongan benda kerja yang pada ujung pahat yang digunakan, sehingga tidak terjadi gesekan relatif antara pahat dengan benda kerja.

Sedangkan untuk tingkat kekasaran N6, ai ra aktual lebih halus. Hal ini dapat 
- Karena sistem yang berada pada level sedang (L/D $4 \geq x \leq 10$ ) dengan rasio panjang terhadap diameter (L/D) untuk pahat utama yang digunakan ( $\varnothing 10 \mathrm{~mm}$ dan $\varnothing 16 \mathrm{~mm}$ ) sebesar 7.5 dan 4. 6875 . Sehingga adanya lenturan atau defleksi pada pahat atau benda kerja relatif lebih kecil

- Pertumbuhan BUE (built up edge) yang lambat karena dalam proses Permesinan menggunakan cairan pendingin.

\section{KESIMPULAN}

1. Tahapan proses pemesinan untuk komponen bracket adalah melalui pengecoran benda kerja terlebih dahulu, kemudian dilakukan penggerindaan sehingga dimensi mendekati dimensi sesuai desain. Selanjutnya proses penghalusan sisi terluar lingkaran $d=125$ $\mathrm{mm}$, setelah itu pengasaran dan penghalusan permukaan sehingga membentuk profil sesuai gambar. Dilanjutkan dengan membuat lubang di tengah dengan diameter akhir $25 \mathrm{~mm}$ sepanjang $53 \mathrm{~mm}$. Setelah selesai benda kerja dibalik, pengerjaan penghalusan sisi terluar lingkaran $\mathrm{d}=63.45 \mathrm{~mm}$ sesuai gambar, dilanjutkan membentuk lingkaran dengan diameter yang lebih kecil serta membuat fillet di sisi terluarnya. Dengan mesin bubut, dilakukan pelebaran lubang di tengah sesuai dengan ukuran dan membuat fillet pada sisi lingkaran $d=125$ $\mathrm{mm}$ dan terakhir melubangi sisi lingkaran $\mathrm{d}$ $=63.45 \mathrm{~mm}$.

2. Kekasaran permukaan aktual yang diperoleh setelah proses pengukuran adalah untuk tingkat kekasaran N5, Raaktual $=0.410 \mu \mathrm{m}$; N6 Raaktual $=0.832 \mu \mathrm{m}$ dan $0.625 \mu \mathrm{m}$.

3. Total waktu Permesinan untuk satu komponen bracket adalah 1 jam 57 menit 25 detik.

\section{DAFTAR PUSTAKA}

[1] Kalpakjian S., S. S. (2010). Manufacturing Procesess for Engineerings Materials: 6th ed. New Jersey: Pearson Prentice Hall, Upper Saddle River.

[2] Rochim, T. (1993). Teori dan Teknologi Proses Permesinan. Bandung: Institut Teknologi Bandung.
[3] Boothroyd, G. (1988). Fundamentals of Metal Machining and Machine Tools. London: CRC Press.

[4] Sujianto. (1998). Perencanaan Proses Permesinan Gear Blank forging Dies dengan Menggunakan CNC Turning. Malang: Jurusan Teknik Mesin FT-UB.

[5] Sriyanto, J. (2012). Analisis Pengaruh Cairan Pendingin Semisintetik dan Soluble Oil terhadap Keausan Pahat High Speed Steel (HSS) pada Proses End Milling, Hal. 9-14.

[6] Zulhendri, G. k. ( Juni 2007). Pengaruh Tipe Pahat dan Arah Pemakanan Permukaaan Berkontur pada Pemesinnan Milling Awal dan Akhir terhadap Kekasaran Permukaan, Vol. 4 No.1 Hal. 16-18.

[7] Rochim, T. (2001). Spesifikasi, Metrologi, dan Kontrol Kualitas Geometrik. Bandung: Institut Teknologi Bandung.

[8] Hricova, J. (2014). Design of End Mill Geometry for Aluminium Alloy Machining, XIX, 2014 (2) 97-105.

[9] Thomas E. French, C. J. (1993). Engineering Drawing and Graphic Technology: International Editions. New York: McGraw-Hill.

[10]Munadi, S. (1980). Dasar-dasar Metrologi Industri. Jakarta: Proyek Pengembangan Lembaga Pendidikan Tenaga Kerja Kependidikan.

[11]G. Takeshi Sato, N. H. (2003). Menggambar Mesin menurut Standar ISO. Jakarta: Pradnya Paramita.

[12] Surdia, T. K. (1984). Teknik Pengecoran Logam. Jakarta: PT Pradnya Paramita.

[13] Modul dan Laporan Praktikum Pengecoran Logam. (2016). Laboratorium Pengecoran Logam Teknik Mesin FT-UB.

[14]A.Schey, J. (1996). Proses Manufaktur: Introduction to Manufacturing Processes. New York: Andi Publishing.

[15] Groover, M. P. (2013). Fundamentals of Modern Manufacturing: Material, Processes, and Systems (Fifth Edition). United States of America: John Wiley \& Sons, Inc. 
